\title{
MATING STRATEGIES OF PHILANTHINE DIGGER WASPS
}

\author{
Howard E. Evans \\ Dept. Zoology \& Entomology \\ Colorado State University
}

\section{Objectives}

This research is part of continuing study of the ethology of digger wasps of the subfamily Philanthinae (Hymenoptera, Sphecidae). At the present time major effort is being directed toward study of mating strategies in the genus Philanthus. There are five species of this genus in Jackson Hole (Evans, 1970). Two of these are more common elsewhere and are being studied elsewhere. Preliminary studies on the remaining three in 1977 revealed striking differences between the three and in one case a mating system unique among digger wasps (Evans \& 0'Neill, 1978). During late June and the first half of July, 1978, we made an effort to further confirm this unique system in $P$. zebratus and to obtain further data on $P$. pulcher, a very common early summer species in Jackson Hole. These ef $\bar{f}$ rorts were successful, but $P$. pulcher also proved unique in some respects and we hope to continue studies of this species in the future. Other species of Philanthus are being studied elsewhere by our group, and we hope to include all of these comparative data in a behavioral monograph on the Philanthinae.

\section{Procedures}

We first checked out known nesting sites of $P$. zebratus and $P$. pulcher along the Snake River. There was a problem with the former, as emergence began about 10 days later than in 1977, and also the site.had been partially covered with piles of earth and stones. (This site is at Deadman's Bar, $14 \mathrm{~km}$ SW of the Moran P.O..) The first male emerged on July 7 , and we were able to follow this aggregation on a day-to-day basis until approximately the peak population was reached on July 15 . We marked all males emerging on a particular day a particular color (Testor's paint) and thus were able to estimate the numbers emerging each day. We also marked all nests made by females as they appeared. Records were kept of the numbers of males flying in the aerial swarms each day. Only one copulation was seen from beginning to end, but this was studied in some detail and photographed.

The second species, $P$. pulcher, was abundant in the area near the Cattle Bridge from the day of our arrival, and we were therefore able to study it in some detail before $P$. zebratus appeared. We located three areas in which females were concentrating their nesting activities. Males established territories on the ground in places near, but not usually in, these nesting areas. A large number of male territories were marked 
and numbered, and many males were individually marked. Territories were censused hourly during the middle of each day to determine which males occupied them. Individual territories were observed for various time periods to determine types of interactions between the resident male and intruders. Several copulations were observed in detail and photographed. We also made several "artificial territories" by clearing a small area of grass (about $0.5 \mathrm{~m}$ in diameter); these were of ten accepted by males. We found that by altering the color of the substrate we were able to alter the apparent desirability of that territory.

\section{Results}

P. zebratus males began emerging July 7 and gradually increased in numbers to 34 on July 11 and to 56 on July 12; after that date others emerged but we discontinued our daily census. The first female emerged on July 9; on July 11 appear to be a critical day, as on that date the first females began digging, and on that date the first males were seen "swarming" (as described by Evans \& $0^{\prime} \mathrm{Ne} i 11,1978$ ). On that date we also observed a single male which established a territory on the ground and maintained it for 1.5 hours. During one 15 minute period, this male made 64 "spontaneous" flights of short duration, made 5 flights in pursuit of intruding males, grappled with one male, and on one occasion marked with pheromone 5 grass stems in one group. Thus this particular male approximated the usual behavior of males in Colorado populations of this same species. We searched carefully for other territorial males but were unable to find any. This particular male returned to the territory the next morning but remained only briefly. Evidently at least some males in this population retain the capacity to maintain a territory, although aerial flights appear to be the major strategy here. Aside from this particular point, our observations during 1978 confirmed those of the previous year. The one copulation observed to go to completion was on July 15, although we had watched continuously for such behavior on previous days. By this date at least 67 nests were active. Thus the evidence suggests that females begin nests and even begin provisioning before they copulate. This point may be difficult to confirm in the field.

P. pulcher males and females were active on June 28 , when we first visited the area. Daily studies were made until July 7 ; after that there was a decline in activity and we made only occasional checks. We marked 32 territories close to the bank of the Snake River and censused these hourly over about 10 days; we also noted numerous other territories and checked these more infrequently. In general, territoriality was serial, in the sense that the "better" territories were occupied essentially every day, for several hours during the warmer part of the day but not always by the same male. Territories were held for an average of $44.4 \mathrm{~min}(\mathrm{~N}=17$; Range $=2-210 \mathrm{~min})$. We were able to observe replacement of one male by another and to follow specific males as they moved from one territory to another. Certain males were obviously more successful in holding 
territories than others; these were often but not always the larger males. Certain territories were also much more "popular" than others. It appeared that the "best" territories are those of appropriate size (0.3-0.5 m diameter), devoid of most vegetation but surrounded by grasses $10-40 \mathrm{~cm}$ high, having a smooth and relatively light-colored soil surface. We made 3 such areas ourselves which had reasonably good male occupancy. We darkened the substrate in one of our best territories and caused it to be abandoned thereafter. Further research is clearly needed to determine what factors attract males to particular territorial sites. We noted several territories not actually on the ground, but on mats of whitish, compacted webbing resting on grass; the webbing apparently resulted from cottonwood "fluff" being submerged in water, drifted into places amongst the grass, and later dried in a mat. Evidently the brilliant white color of these mats is attractive to males.

The six copulations of $P$. pulcher we observed were all on plants at the edge of territories. As in other species of this genus, males periodically marked stems at the edge of the territory with pheromone. The evidence suggests that these marked stems do not attract other males but do attract females. As compared to other species of Philanthus, pulcher males mark intensively. For example, in a one-hour period, one male marked 97 times, another series of 3 males 102 times. Duration of copulation varied from 4 to 7 minutes.

While defending territories, males fly after any small insects that cross their territory, although butting and grappling occur primarily with conspecifics. We recorded many interactions with other insects, and on several occasions found that males which approached robber flies (Asilidae) were seized and fed upon. There are few published records of differential mortality between the sexes, although it is to be expected that territorial males will expose themselves to predation of this type. In this instance there is evidence that robber flies are attracted to areas where males are territorial. A paper is in preparation on this phenomenon in several species of Philanthus (Gwynne and O'Neill, MS).

We also made brief observations on the nesting behavior of Crabro largior, which occurred in small numbers in the $\underline{P}$. zebratus site. We had studied this species previously in New Mexico, and we noted no differences between these two widely separate aggregations except as to type of prey. However, this probably simply reflected the fact that the more usual prey of Crabro (horseflies and stiletto flies) were scarce in Jackson Hole and tachina flies were, therefore, being employed almost exclusively.

\section{Conclusions}

Quantitative studies of mating systems in two species of Philanthus occurring in Jackson Hole have demonstrated that in one species, $\underline{P}$. pulcher, males establish territories away from the nesting sites and copulations occur on the edge of these territories. On the other hand, in $P$. zebratus males participate in aerial swarms and mating is initiated at the level of the swarm. However, one male was found to be territorial for a short time within the nesting area, approximating the usual mating 
system of this species in several Colorado localities. In pulcher, territoriality is largely serial, that is, a succession of males occupy the "best" territories. More research is needed to clarify the factors determining territory quality in this species.

\section{Acknowledgments}

This research was supported in part by National Science Foundation grant BNS76-09319. Assistance of personnel of the National Park Service and of the University of Wyoming-National Park Service Research Center is acknowledged gratefully. Those participating in this research aside from the principal investigator were: Mary Alice Evans, Kevin M. O'Neill, and Darryl T. Gwynne.

\section{$\underline{\text { Literature } \text { Cited }}$}

Evans, H.E. 1970. Ecological-behavioral studies of the wasps of Jackson Hole, Wyoming. Bul1, Mus. Comp. Zool. Harvard, ]40: 451-511.

Evans, H.E., and K.M. O'Neill. 1978. Alternative mating strategies in the digger wasp Philanthus zebratus Cresson. Proc. Nat. Acad. Sci., 75: $1901-1903$.

Gwynne, D.T., and K.M. O'Neill. (In Prep.). Terrltoriality results in sex-biased predation in digger wasps. 